\title{
Influences on Adoption of Greenhouse Gas Reduction Targets among US States, 1998-2008
}

\author{
Tabitha M. Cale ${ }^{1}$, Margaret A. Reams ${ }^{2}$ \\ ${ }^{1}$ Department of Political Science, Louisiana State University, Baton Rouge, USA \\ ${ }^{2}$ Department of Environmental Sciences, Louisiana State University, Baton Rouge, USA \\ Email:mreams@1su.edu
}

Received October $7^{\text {th }}, 2012$; revised November $17^{\text {th }}, 2012$; accepted November $29^{\text {th }}, 2012$

\begin{abstract}
While the United States has not established federal regulations for greenhouse gas (GHG) reduction targets, many US states have adopted their own standards and guidelines. In this study we examine state adoption of targets for GHG reductions during the ten-year period of 1998-2008, and identify factors that explain variation in target adoption. Potential influences are drawn from research from the public policy formulation and diffusion literature, and from studies specific to climate policy adoption. Potential influences on GHG reduction efforts among US states include socioeconomic attributes of residents, political and ideological orientations of citizens and state government, interest group activities, environmental pressures, and proximity to other states that have adopted GHG reduction targets. The findings of the multinomial logistic regression analysis indicate that states are more likely to adopt GHG reduction targets if they share a border with another state with a similar climate program and if their citizens are more ideologically liberal. Other factors including socioeconomic resources and interest group activities were not found to be associated with policy adoption. The findings yield insights into the conditions under which states are more likely to take action to reduce GHG's, and are relevant both to state policy makers and residents with an interest in climate planning, and for researchers attempting to estimate future greenhouse gas reduction scenarios.
\end{abstract}

Keywords: Climate Change Policy; State Climate Planning; Greenhouse Gases (GHG's); State Environmental Policy

\section{Introduction}

The 1997 Kyoto Protocol was not ratified by the US Senate and, to date, no federal targets for greenhouse gas (GHG) reductions have been set. In this context, many states have been proactive in establishing their own GHG reduction targets. The potential greenhouse gas (GHG) reductions from state actions are significant. Lutsey and Sperling (2008) calculated that if all of the state and city emissions targets in place were to be achieved, US GHG emissions could be stabilized at 2010 levels as soon as 2020. This would be a substantial reduction in GHG's and could be accomplished without federal mandates.

Adoption of climate-change mitigation policies is a complex challenge for state and federal policy makers for several reasons. As W. Neil Adger (2009) pointed out, the scale and interconnectedness of the impacts of climate change are growing each year, so that "the window to act" may be shorter than we realize. Despite a possible sense of urgency, it is difficult to conduct cost-benefit type analyses of various mitigation strategies because the precise extent and timing of future damages are difficult to determine. As a result, the future benefits to be gained through mitigation programs are difficult to quantify fully, while the present-day costs of some of the options, including implementing specific GHG reduction targets, are easier to determine. In this context, it can be hard to summon the political will necessary to address climate change mitigation, especially given the existence of other compelling public problems competing for limited public resources.
Also, climate change planning is made more difficult by a tendency among policy makers in the US to display a "shortterm bias" in decision making. Consideration of problems and associated damages likely to occur more than four years in the future tend to be differed to later administrations, while more pressing issues are considered and acted upon in the present (Vig \& Kraft, 2010).

Given these challenges and disincentives, why have some US states taken steps to address climate change while others have not? In this paper we examine the adoption of GHG reduction targets among US states during the ten year period after Kyoto, from 1998 to 2008 . Our central research objective is to identify key factors that may explain variation in state officials' decisions to adopt state-level GHG reduction targets.

\section{Related Research}

In order to identify potential influences on state actions, we consider several themes within the political science public policy literature. First, researchers have examined patterns of policy "diffusion" among states within a geographic region and from one level of government to another. This "policy learning" and diffusion literature has examined "horizontal" diffusion of policy across the same level of government (Volden, 2006; Berry \& Baybeck, 2005; Berry \& Berry, 1990; Mooney \& Lee, $1995)$ as well as "vertical" diffusion of policy between different levels of government (Shipan \& Volden 2006). Studies of horizontal policy diffusion generally have concluded that policies 
"seem to spread between states that share a region and between states that share borders". (Ingle et al., 2007: p. 607).

Other researchers have turned to factors within the state or “internal determinants" as key influences on officials' decisions to adopt certain policies (Gray, 1973, 1994; Fredriksson \& Millimet, 2002). This orientation is reflected in Ingle and colleagues' statement that "states adopt politics only when their own political, economic, and social environments are favorable" (Ingle et al., 2007: p. 607).

Of course, diffusion across state or regional borders is not mutually exclusive with the view that state policy adoption also is influenced by contextual factors within each state. So, recently, a third approach to understanding policy diffusion has emerged, combining elements of the diffusion literature and elements of the internal determinants literature; policies may spread across states with similar political party identifications and other internal characteristics and need not necessarily share a border or be in the same region as a state that is being emulated (Gray \& Hanson, 2008). For example, Volden found that "similarities based on ideological leanings, per-capita income... and budgetary considerations" were all significantly related to policy diffusion (Volden, 2006: p. 310).

A second broad theme examines potential linkages between environmental policy adoption and the level of enforcement of existing environmental regulations. Woods (2006) argues that environmental regulation is particularly susceptible to a "race to the bottom" scenario since negative externalities of pollution could be left to other jurisdictions to address, while the nearby state with the least regulation could benefit economically. In other words, states could have an incentive to avoid adopting strict regulatory standards, in order to attract polluting Industries and thereby gain a competitive economic advantage (Ringquist, 1993).

Woods notes that there is "little evidence that firms relocate on the basis of regulatory cost differentials" but that "survey evidence suggests that regulators believe they do and that this belief appears to affect environmental policy" (Woods, 2006: p. 177). This apparent paradox may exist either because policymakers are unaware of all factors involved in a decision for a given firm to relocate, or because regulators are under pressure from industry lobbyists to regulate as little as possible, even when firms have no intention of relocating.

In an examination of EPA data on the enforcement of federal pollution laws, Konisky (2007) concludes that states respond to the regulatory behavior of others states, but those responses tend to vary. Whereas some states would respond to the more stringent regulatory stance of neighboring states, for example, and "race to the top", actually strengthening their environmental standard and regulations, others may tend to maintain less stringent standards.

In addition to these potential influences on state GHG reduction efforts, the political and ideological perspectives of citizens and policy makers concerning climate change may be especially relevant (McCright \& Dunlap 2003). The Pew Research Center for the People and The Press, in a survey conducted April 23-27, 2008, found a significant partisan divide between Republicans and Democrats concerning attitudes toward climate change. When asked if there is "solid evidence of global warming" $84 \%$ of Democrats and $75 \%$ of Independents agreed, as compared to only $49 \%$ of Republican respondents. Democrats and Independents (58\% and 50\% respectively) also were more likely to believe that global warming is anthropogenic caused by human activity, than Republicans (27\%). When respondents were categorized into college graduates and noncollege graduates, the partisan divide became even larger. Asked if "global warming is happening because of human activity", $31 \%$ of Republicans who did not graduate from college agreed as compared to $19 \%$ of those who did graduate from college. Fifty-two percent of Democrats who did not graduate from college agreed as compared to $75 \%$ of those who did, and 48 percent of Independents who did not graduate from college, and $57 \%$ of those who did, agreed that global warming is occurring as a result of human activity.

\section{Research Questions}

In light of findings and insights from these studies, we pose several research questions.

Question 1: Are states that share a border with one or more other states with GHG reduction targets more likely to adopt their own GHG reduction targets?

In addition we want to examine possible "internal determinants" of state adoption GHG reduction targets. We are particularly interested in whether the differences in opinions concerning the causes and consequences of climate change between Democrats and Republicans may carry over into state efforts to limit GHG's.

Question 2: Are states with liberal citizens and/or governments more likely to adopt GHG Reduction Targets?

Additional internal attributes or conditions such as socioeconomic and environmental conditions should be examined as well. Thus, we pose the following questions:

Question 3: Are states with higher levels of poverty less likely to adopt GHG Reduction Targets?

Question 4: Are states with higher levels of toxic releases less likely to adopt GHG Reduction Targets?

Also, the possible influence of a "race to the bottom (or top)" motivation should be explored. Specifically the combination of a state's industrial pollution level and the climate policy actions of neighboring states may be a relevant consideration. Thus,

Question 5: Are those states that have lower levels of toxic releases, and also share a border with a state with GHG reduction targets, more likely to adopt GHG Reduction Targets?

A final set of potential influences include interest group activities within each state. Setting targets for GHG emissions could affect a range of economic interests including those involved in energy production and delivery, building and construction, and infrastructure and transportation planning. Given that these interests may be competing with environmental groups for influence in the establishment of new climate policies, it is useful to examine potential associations between political donations from major interest groups and state adoption of GHG reduction standards. We assume that environmental interest groups would be more likely to support climate change policies, in general, and traditional energy interests (oil and gas industry) may be hesitant to accept increased regulation concerning GHG's. Thus, we pose the following questions:

Question 6: Are states with higher levels of political contributions from environmental and alternative energy interest groups more likely to adopt GHG Reduction Targets?, and;

Question 7: Are states with higher levels of political contributions from traditional energy interest groups less likely to adopt GHG Reduction Targets? 


\section{Data and Methods}

The analysis uses panel, cross-sectional data to examine state adoption of GHG reduction targets from 1998-2008. The dependent variable in this analysis is whether a state had GHG reduction targets in place during each year of the ten-year time frame. Data to construct the dependent variable came from the Pew Center on Global Climate Change. The variable is coded as "0" (zero) in years the state had not adopted GHG targets, and " 1 " (one) for years in which targets were present. The tenyear period was selected because it was a time of heightened public debate concerning climate change, including the 1997 Kyoto Protocol, the US Senate's subsequent vote not to ratify the treaty, and the release of the influential film, An Inconvenient Truth.

The independent variables include one indicator of possible "horizontal policy diffusion" or the spreading of the GHG reduction target policy between states with shared borders. We constructed the variable "Border State" using information provided by the Pew Climate organization. The variable was coded " 0 " if no bordering state had a GHG reduction target within the year, and coded " 1 " if at least one bordering state had targets in place that year. Concerning the internal characteristics of the state, the variables "Liberal Government" and "Liberal Citizens", were included. These variables were constructed by Berry et al. in 1996 and have been updated annually.

The variable Toxic Release Inventory (TRI) releases was gathered from the EPA for each year, as a measure of environmental pollution from regulated manufacturing industries within each state. We included the percentage of citizens below the federal poverty level as an indicator of economic conditions within the state. The variable "Poverty" was taken from the US Census for the year 2005. Contributions from environmental and alternative energy groups to state political parties and candidates ("Environmental Interest") and contributions from traditional oil and gas energy groups ("Energy Interest") were compiled using data from the Followthemoney.org website. All of the independent variables with the exception of "Poverty" were compiled for each year from 1998-2008.

The data were analyzed using a multinomial logistic regression analysis using SPSS version 15.0. The logistic model is an appropriate method to determine the relative associations of each of the independent variables with the dichotomous dependent variable

\section{Results and Discussion}

Seventeen states had adopted GHG reduction targets by 2008 , with California being the first state to formulate specific targets. Thirty-three US states had not adopted reduction targets. The 17 states with GHG reduction targets are listed in alphabetical order:

Arizona, California, Connecticut, Florida, Hawaii, Illinois, Maine, Massachusetts, Minnesota, New Hampshire, New Jersey, New Mexico, New York, Oregon, Rhode Island, Vermont and Washington.

The logistic model yielded several interesting results concerning the relative associations between the independent variables and states' adoption of the GHG reduction targets. The variables most significantly associated with the policy action are "Border State", "Liberal Citizens," and the interaction or combination of "Low Toxin" and "Border State" variables. The results of the analysis are summarized below in Table 1.

Question 1: Are states that share a border with one or more other states with GHG reduction targets more likely to adopt their own GHG reduction targets? Yes, the results indicate that neighboring states tend to adopt similar reduction efforts. This finding lends support to the horizontal policy diffusion explanation that public policies across a variety of issue areas are likely to be picked up and implemented by policy makers in neighboring states, consistent with earlier findings by Gray (1973, 1994) and Turner and Cassel (2007). This finding offers evidence that the process of formulating and implementing climate change policies at the state level is similar to and influenced by the same forces and influences that drive policy diffusion in other subject areas.

Question 2: Are states with more liberal citizens and governments more likely to adopt GHG reduction targets? Yes, to some extent the findings support this linkage. The results indicate that states with more liberal citizens are much more likely to have adopted GHG reduction targets. The liberal government variable was not found to be significantly associated with the targets, however. The findings suggest that the extreme partisan divisions in opinions concerning climate change documented by the Pew research group and Berry et al. (1998) probably have affected state adoption of GHG reduction targets, with states with more liberal citizens being much more likely to attempt to mitigate climate change.

Question 3: Are states with higher levels of poverty less likely to adopt GHG reduction targets? No, the findings do not offer evidence that states with larger numbers of economically disadvantaged citizens were less able or willing to set GHG reduction targets from 1998-2008. We included this variable to examine whether policy makers in states where poverty is more of a problem may be reluctant to introduce climate change mitigation programs because the efforts may be perceived as imposing regulatory costs that may affect private sector employment. However, the findings indicate no such reluctance on the part of officials in states with higher poverty rates. The results suggest that poverty within a state may not introduce significant obstacles to $\mathrm{GHG}$ reduction efforts.

Question 4: Are states with higher levels of toxic releases less likely to adopt GHG reduction targets? No, the analysis yielded no evidence that levels of toxic releases, on their own,

Table 1.

Logistic analysis results: State adoption of greenhouse gas targets.

\begin{tabular}{ccc}
\hline & Coefficient & SE (Robust) \\
\hline Border State $[+]$ & 1.0221 & $0.4781^{*}$ \\
Liberal Government $[+]$ & 0.0118 & 0.0094 \\
Liberal Citizens $[+]$ & 0.0674 & $0.0202^{* * *}$ \\
Toxic Releases $[-]$ & 0.0646 & 0.7323 \\
Poverty $[-]$ & 0.0180 & 0.0792 \\
Environmental Interest $[+]$ & 0.1777 & 0.1458 \\
Energy Interest $[-]$ & 0.0066 & 0.0393 \\
Low Toxin Border $[+]$ & 3.4558 & $1.0667^{* * *}$ \\
Constant & -7.0661 & $1.5608^{* * *}$ \\
\hline
\end{tabular}

Note: $\mathrm{N}=537$ (State-years); Prob $>$ chi2 $=0.0000$; Pseudo R2 $=0.5509 ;{ }^{* * *} p<$ $0.001,{ }^{* *} p<0.01,{ }^{*} p<0.05$ (one-tailed tests). 
are related to adoption of GHG reduction targets. In other words states with more industrial manufacturing activity that results in higher levels of toxic emissions are not any less likely to develop GHG reduction targets.

Question 5: Are those states that have lower levels of toxic releases, and also share a border with a state with GHG reduction targets, more likely to adopt GHG reduction targets? Yes, the interaction or combination of lower TRI emissions and the presence of a border state with a GHG a reduction target program, was found to be significantly associated with adoption of reduction targets. States with low levels of toxic emissions may be influenced by the GHG reduction actions of neighboring states. This finding offers some evidence of a "race to the top" influence among states with lower levels of toxic emissions from regulated manufacturing industries.

Question 6: Are states with higher levels of political contributions from environmental and alternative energy interest groups more likely to adopt GHG reduction targets? and,

Question 7: Are states with higher levels of contributions to state legislators from traditional energy interest groups less likely to adopt GHG reduction targets?

Neither environmental interest group contributions, nor energy interest group contributions had a significant effect on state adoption of GHG targets. One explanation for this finding is that lobbyists for traditional oil and gas enterprises and those representing alternative energy companies, may be engaged in issues other than whether a state adopts GHG reduction targets. Also, these interest groups' positions on GHG reduction efforts may not be as polarized as the general view of average citizens concerning climate change. Finally, while setting GHG reduction targets may be viewed as a first step in addressing climate change, these programs may not introduce onerous measures that would be resisted by oil and gas energy interests at this time. In fact "no regrets" policies and actions, such as those that require or encourage greater energy efficiency, can introduce benefits in addition to reduced GHG levels, and may enjoy more widespread support among various interest groups. Additional information about the stringency of state climate change mitigation programs will be needed to examine this question more fully.

\section{Conclusion}

This examination of states' adoption of GHG reduction targets yielded insights into the conditions under which states are more likely to take action to address climate change. In light of the polarization of public attitudes and opinions concerning the causes and consequences of global climate change, we were particularly interested in the extent to which political ideology may be affecting state actions.

The results of the logistic regression analysis suggest that the most important factor in explaining variation in GHG reduction target adoption is whether the state is located next to a state whose officials have adopted a similar program. This finding supports the "horizontal diffusion" of state actions to reduce GHG's. Also, those states with relatively low levels of toxic pollution, and also are in close proximity to another state with GHG reduction targets, are more likely to implement similar efforts, providing evidence of a possible "race to the top" influence at work.

Certainly, the influence of political ideology is confirmed by the finding that those states with more liberal voters and citi- zens are much more likely to have set specific targets for reductions in GHG's. This suggests that the polarization among the public concerning climate change may be affecting the choices made by state officials as to whether to engage in climate change mitigation efforts.

In future studies it would be useful to examine the specific GHG reduction targets adopted by the states, especially any incentives that may be offered to encourage GHG reductions. In addition, considering whether a state is a member of a regional climate change alliance like the Regional Greenhouse Gas Initiative in New England, and the Western Climate Initiative, may be useful. Also, the inclusion of variables related to fossil fuel energy production and consumption, as well as alternative energy production and consumption may be relevant in understanding why some states engage in efforts to reduce GHG's and others do not. In addition, a look at the degree to which neighboring states with similar climate policies may also have similar ideological orientations may yield additional insight into policy diffusion across states. Finally, close examinations of leader and laggard states, through case studies, would help to shed more light on specific contextual factors affecting adoption of climate change policies.

States have an important role to play in devising policies to address climate change, both in terms of mitigation strategies to reduce GHG's entering the Earth's atmosphere, and in helping communities to adapt to some of the consequences of a warming planet, such as planning for extreme weather events. This analysis provides insight into some of the influences at work as state policymakers grapple with whether and how to address climate change, with little direct guidance from the federal government. As a result the findings are relevant to theorists and state policy makers with an interest in climate planning, and for researchers attempting to estimate future greenhouse gas reduction scenarios.

\section{REFERENCES}

Adger, W. N. (2009). Commentary. Environment and Planning A, 42, 2800-2805. doi:10.1068/a42244

Berry, F., \& Berry, W. (1990). State lottery adoptions as policy innovation: An event history analysis. American Political Science Review, 84, 395-415. doi:10.2307/1963526

Berry, W., \& Baybeck, B. (2005). Using geographic information systems to study interstate competition. American Political Science Review, 99, 505-519. doi:10.1017/S0003055405051841

Berry, W., Ringquist, E., Fording, R., \& Hanson, R. (1998). Measuring citizen and government ideology in the American states, 1960-1993. American Journal of Political Science, 42, 327-348. doi: $10.2307 / 2991759$

Erickson, R., Wright, G., \& McIver, J. (1993). Statehouse democracy: Public opinion and policy in the American states. New York: Cambridge University Press.

Fredriksson, P. G., \& Millimet, D. (2002). Strategic interaction and the determination of environmental policy across US states. Journal of Urban Economics, 51, 101-122. doi:10.1006/juec.2001.2239

Gray, V. (1973). Innovations in the States: A diffusion study. American Political Science Review, 67, 1174-1191. doi:10.2307/1956539

Gray, V. (1994). Competition, emulation, and policy innovation. In L. C. Dodd, \& L. C. C. Jillson (Eds.), New perspectives on American politics (pp. 230-248). Washington DC: Congressional Quarterly Press.

Gray, V., \& Hanson, R. (2008). Politics in the American states: A comparative analysis (9th ed.). Washington DC: Congressional Quarterly Press.

IPCC (2007). Summary for Policymakers. In S. Solomon, D. Qin, M. 


\section{T. M. CALE, M. A. REAMS}

Manning, Z. Chen, M. Marquis, K. B. Averyt, M. Tignor, \& H. L. Miller (eds.), Climate change 2007: The physical science basis. Contribution of working group I to the fourth assessment report of the intergovernmental panel on climate change. Cambridge and New York: Cambridge University Press.

Konisky, D. (2007). Regulatory competition and environmental enforcement: Is there a race to the bottom? American Journal of Political Science, 51, 853-872. doi:10.1111/j.1540-5907.2007.00285.x

Lutsey, N., \& Sperling, D. (2008). America's bottom-up climate change mitigation policy. Energy Policy, 36, 673-685.

doi:10.1016/j.enpol.2007.10.018

McCright, A., \& Dunlap, R. (2003). Defeating Kyoto: The conservative movement's impact on US climate change, policy. Social Problems, 50, 348-373. doi: $10.1525 / \mathrm{sp} .2003 .50 .3 .348$

Moore, M. (2007). Energy \& environmental giving in the States. National Institute on Money and State Politics, 1-10. URL (Last checked 23 February 2011) http://www.followthemoney.org

Pew Center on Global Climate Change (2009). President Obama and climate change. URL (Last checked 26 February 2011).

http://pewclimate.org/obama-administration

Pew Research Center for the People and the Press (2008). A deeper partisan divide over global warming. URL (Last checked 26 Febru- ary 2011). http://people-press.org/reports/pdf/417.pdf

Ringquist, E. (1993). Does regulation matter? Evaluating the effects of state air pollution control programs. Journal of Politics, 55, 10221045. doi: $10.2307 / 2131946$

Shipan, C., \& Volden, C. (2006). Bottom-up federalism: The diffusion of antismoking policies from US cities to states. American Journal of Political Science, 50, 825-843.

doi:10.1111/j.1540-5907.2006.00218.x

Vig, N., \& Kraft, M. (2010). Environmental policy: New directions for the twenty-first century. Washington DC: Congressional Quarterly Press.

Vogel, D. (1995). Trading up: Consumer and environmental regulation in a global economy. Cambridge, MA: Harvard University Press.

Volden, C. (2006). States as policy laboratories: Emulating success in the children's health insurance program. American Journal of Political Science, 50, 294-312. doi:10.1111/j.1540-5907.2006.00185.x

Woods, N. (2006). Interstate competition and environmental regulation: A test of the race to the bottom thesis. Social Science Quarterly, 86, 792-811.

Wright, G., Erikson, R., \& McIver, J. (1987). Public opinion and policy liberalism in the American states. American Journal of Political Science, 31, 980-1001. doi:10.2307/2111232 